\title{
2017 ESS Safety Forum to be held February 22-24 in the United States
}

https://share.sandia.gov/ess/ess-safety-forum-2017

$\mathrm{M}$ eeting the Challenge: 2017 Energy Storage System Safety Forum (2017 ESS Safety Forum) will be held February 22-24, 2017, in New Mexico, USA.

The main objective is to provide a platform to discuss the current state of ESS safety and mitigation strategies for improving cell to system safety and reliability. This open forum will allow researchers an opportunity to present their work in ESS, including research and development, code standards and regulations (CSRs), as well as gaps in CSRs that affect deployment of energy storage. This will encompass, but is not limited to, developing inherently safe battery chemistries, energy-storage software, power electronics and cyber security to improve safety and monitoring, designing safe systems, codes and standards, signage, and commissioning.

More information can be accessed from the forum website at https://share. sandia.gov/ess/ess-safety-forum-2017 or by email at ESSforum@sandia.gov.

OP2017 to be held June 19-23 in Canada http://op2017.org

$\mathrm{T}$ he 12th International Conference on Optical Probes of Organic and Hybrid Semiconductors (OP2017) will be held June 19-23, 2017, in Québec City, Canada. The co-chairs are Carlos Silva of Université de Montréal, Canada; and Stéphane KénaCohen of École Polytechnique de Montréal, Canada.

The scope of the conference is a variety of excited state phenomena in technologically important materials and biosystems, including size-dependent and time-dependent electronic interactions, excited state dynamics, strong light-matter interactions, quantum confinement, photocarrier transport, and novel spectroscopic techniques. The objective is to place emphasis on the generality of the phenomena rather than specifics of the systems and optical measurements.
Topics include

- Organic and polymeric materials (photophysics, chemistry, and dynamics)

- Energy transport and exciton annihilation processes

- Organic/polymeric electronic devices (OLEDS, OPV)

- Photophysics and applications of hybrid organometal perovskite materials

- Thermally activated delayed fluorescence in OLEDs

- Organometallic complexes (photophysics and applications)

- Semiconductor nanocrystals and metal nanoparticles (hybrid devices and novel physical phenomena)

- Organic and inorganic nanostructured photovoltaic phenomena (physics, chemistry, and devices)

- Optical properties of carbon allotropes

- Photophysics of 2D atomic-layered materials
- Molecular and supramolecular ordered assembly at nanoscales

- Novel optical probes for condensedmatter materials research

- Singlet fission

- Spin dynamics in organic systems

- Photophysics of bioorganic materials and luminescent optical probes

Confirmed plenary speakers are Vahid Sadoghdar of the Max Planck Institute for the Science of Light, and Friedrich-Alexander-Universität ErlangenNürnberg, Germany; Chihaya Adachi of Kyushu University, Japan; and Greg Scholes of Princeton University, USA.

The abstract submission deadline is February 29. The early bird and presenting author registration deadline is April 18. More information can be accessed from the conference website at http://op2017.org or by email at OP2017@conferium.com.
Y UCOMAT 2017 will be held September 4-8, 2017, in Herceg Novi, Montenegro. It is organized by the Materials Research Society of Serbia.

Five symposia will comprise invited plenary lectures, oral presentations, and poster presentations: Symposium A-Advanced Methods in Synthesis and Processing of Materials; Symposium B-Advanced Materials for High-Technology Application;
Symposium C-Nanostructured Materials; Symposium D-EcoMaterials and Eco-Technologies; and Symposium E-Biomaterials. The conference will also feature a tutorial for young researchers and an exhibition of synthesis and characterization equipment.

Awards will be presented to the authors (preferably members younger than 35) of the best oral and poster presentation at the conference, and also to the authors of highly rated $\mathrm{PhD}$ theses defended between two conferences.

The deadline for abstract submission is May 1. Preregistration ends June 15 , and regular registration ends July 31. More information can be accessed from the conference website at www. mrs-serbia.org.rs/index.php/yucomat$2017 \mathrm{~m}$ or by email at yucomat@ mrs-serbia.org.rs. 